\title{
Role of Interventional Radiology in Management of Chronic Shoulder Pain
}

\section{Mohamed M. Ahmed ElKardosy ${ }^{1, *}$ M.B.B.Ch, Ahmed Abdelfattah Mahmoud ${ }^{2}$ MD,} Ahmed M. Zidan ${ }^{1}$ MD. and Gamal Attia Elsawy ${ }^{3}$ MD.

\author{
* Corresponding Author: \\ Mohamed M. Ahmed ElKardosy \\ Dr.Kardosy@gmail.com
}

Received for publication June 17, 2021; Accepted July 23, 2021; Published online July 23, 2021.

Copyright The Authors published by Al-Azhar University, Faculty of Medicine, Cairo, Egypt. Users have the right to read, download, copy, distribute, print, search, or link to the full texts of articles under the following conditions: Creative Commons Attribution-Share Alike 4.0 International Public License (CC $B Y-S A$ 4.0)

doi: 10.21608/aimj.2021.81152.1505

${ }^{I}$ Radio-diagnosis Department, Police Authority Hospitals, Egypt.

${ }^{2}$ Radio-diagnosis Department Faculty of Medicine, Al-Azhar University Cairo, Egypt.

${ }^{3}$ Orthopedic Surgery Department, Faculty of Medicine, Al-Azhar

University Cairo, Egypt.

\begin{abstract}
Background: Shoulder pain is a frequent musculoskeletal condition in the overall population, with incidence of $6.7-66.7$ percent.

Aim of the work: to estimate the interventional radiology role in management of chronic shoulder pain.

Patients and methods: This prospective study included (60) patients with chronic shoulder pain. Regional injection had been done guided by ultrasound, fluoroscopy \&/or CT for e.g: hydrodilatation of the glenohumeral capsule, hydro-dissection of the subacromial bursa, neurolysis of suprascapular \& subaxillary nerves.

Results: Full technique has a significant higher improvement in VAS, ROM and SPADI than partial technique. High volume injection has a significant higher improvement in VAS, ROM and SPADI than Low volume injection. Intra-articular injection has a significant higher improvement in VAS, ROM and SPADI than Extra-articular injection.

Conclusion: We can conclude that interventional radiology has an effective role in chronic shoulder pain treatment.
\end{abstract}

Keywords: Interventional Radiology; Chronic Shoulder Pain; Intraarticular steroid injections.

Disclosure: The authors have no financial interest to declare in relation to the content of this article. The Article Processing Charge was paid for by the authors.

Authorship: All authors have a substantial contribution to the article.

\section{INTRODUCTION}

Type 1 diabetes (T1D) is one of the most common Shoulder pain is a frequent musculoskeletal condition in the overall population, with incidence of $6.7-66.7$ percent. ${ }^{1}$

Chronic shoulder pain is caused by several etiologies: from rotator cuff disease to peripheral nerve entrapment. ${ }^{2}$

Advancement in ultrasound (US) technologies enables static and dynamic assessment and guiding on treatment modalities. ${ }^{3}$

Obviously, there is a greater safety range for intervention approaches under US guideline. Depending on the intended location, doctors may simply pick the needle insertion procedure and so prevent injuries to the surrounding structures. It is vital to realise that US guidance intervention should not be assumed to be an appropriate target alone; they provide full guidance on therapy beginning with clinical practice. ${ }^{4}$

Distinsion of the glenohumeral joint by fluid, which can decrease pain by widening the range of motion and damage the joint capsule and can decrease the intraarticular inflammation by intraarticular steroid injection. ${ }^{5}$

Intraarticular distension has been demonstrated to enhance short-term pain and function, although this effect is sustained up to 3 months, and the outcome of cases with diabetes is less than that of nondiabetics. $^{6}$

The most beneficial strategy is intra-articular steroid injection which leads to a quick decrease in pain and an enhancement in the mobility and capacity to do physical treatment.

We aimed in this work to assess the interventional radiology role in management of chronic shoulder pain.

\section{PATIENTS AND METHODS}

This prospective research involved sixty cases with chronic shoulder pain and was conducted at Radiodiagnosis Department, Faculty of Medicine, AlAzhar University during the period from 1 January 2020 to 1 January 2021. 
The study was accepted by the Ethics Board of AlAzhar University and all study individuals give an informed written consent.

\section{Inclusion criteria:}

Any patients with chronic shoulder pain, limitation / restricted of movements of the shoulder joint, patient cannot lie on the shoulder due to pain \& who are showing cacific tendonitis.

\section{Exclusion criteria:}

Patients with poor general and mental condition.

Local infection.

Recurrent shoulder dislocation

Autoimmune inflammatory diseases.

Pregnancy (when using Fluoroscopy guided injection).

Patients refuse to participate

Malignancy.

\section{Methods:}

All patients subjected to the following:

Full history taking and pre-procedure diagnostic MRI examination.

Musculoskeletal assessment (visual analogue scale and range of movement) of shoulder joint before the injection, immediately after, during the first $24 \mathrm{~h}$ and after 2 weeks ${ }^{(2)}$.

Injection of the shoulder could be part of the treatment of the shoulder pain, especially if the pain is more than what patient can handle, shoulder pain will probably hinder the progress of the therapy.

The injection could be done by posterior, lateral, or anterior approaches.

Regional injection had been done guided by ultrasound, fluoroscopy \&/or CT for e.g: hydrodilatation of the gleno-humeral capsule, hydro-dissection of the subacromial bursa, neurolysis of suprascapular \& subaxillary nerves.

\section{Statistical Analysis of Data:}

The collected data organized, tabulated and statistically analyzed using statistical package for social sciences (SPSS) version 22 (SPSS Inc, Chicago, USA). For qualitative data, frequency and percent distributions was calculated. For quantitative data, mean, standard Error (SE), minimum and maximum was calculated. Statistical significance was defined as $\mathrm{P}$ value $<0.05$.

\section{The following tests were done:}

Chi-square test: For categorical variables, to compare between different groups.

The one-way analysis of variance (ANOVA): is used to determine whether there are any statistically significant differences between the means of data at basal, immediately, $1^{\text {st }} 24$ hour and 2 weeks postinjection.

\section{RESULTS}

This study included 60 patients with chronic shoulder pain, the majority were males $34(56.7 \%)$. Their mean of age was 65.17 year.
Considering diagnosis, $25 \quad(41.7 \%)$ patients diagnosed as frozen shoulder, 20 (33.3\%) Subacromial bursitis and $15(25 \%)$ as Bicepital tenosynovitis. Regarding Radiological interventions, patients with frozen shoulder treated by partial technique $10(16.7 \%)$ and full technique 15 (25\%), patients with Subacromial bursitis treated by Low volume injection $5(8.3 \%)$ and high volume injection $15(25 \%)$ while in patients with Bicepital tenosynovitis treated by Extra-articular injection 5 $(8.3 \%)$ and intra-articular injection 10 (16.7\%) (Table 1).

There is a significant difference between basal, immediately, 1st $24 \mathrm{hr}$ and 2 weeks VAS after injection at movement, sleep and total mean score while there is no significant difference between basal, immediately, 1 st $24 \mathrm{hr}$ and 2 weeks VAS after injection at rest (Table 2).

Full technique has significantly higher improvement in VAS, ROM and SPADI than partial technique $(\mathrm{p}<$ 0.05) (Table 3).

High volume injection has significantly higher improvement in VAS, ROM and SPADI than Low volume injection $(\mathrm{p}<0.001)$ (Table 4).

Intra-articular injection has significantly higher improvement in VAS, ROM and SPADI than Extraarticular injection $(\mathrm{p}<0.001)$ (Table 5).

\begin{tabular}{|c|c|c|}
\hline \multirow{2}{*}{ Radiological interventions } & \multicolumn{2}{|c|}{ Cases $(n=60)$} \\
\hline & No & $\%$ \\
\hline \multicolumn{3}{|c|}{ Frozen shoulder $(n=25)$} \\
\hline Partial technique* & 10 & $16.7 \%$ \\
\hline Full technique $^{\#}$ & 15 & $25 \%$ \\
\hline \multicolumn{3}{|c|}{ Subacromial bursitis $(n=20)$} \\
\hline Low volume injection & 5 & $8.3 \%$ \\
\hline High volume injection & 15 & $25 \%$ \\
\hline \multicolumn{3}{|c|}{ Bicepital tenosynovitis $(n=15)$} \\
\hline Extra-articular injection & 5 & $8.3 \%$ \\
\hline Intra-articular injection & 10 & $16.7 \%$ \\
\hline
\end{tabular}

*Partial technique $=$ hydrodilatation of the glenohumeral capsule, hydro-dissection of the subacromial bursa.

\#Full technique $=$ hydrodilatation of the glenohumeral capsule, hydro-dissection of the subacromial bursa and neurolysis of suprascapular \& subaxillary nerves.

Table 1: Distribution of patients as regard to radiological interventions 


\begin{tabular}{|c|c|c|c|c|c|}
\hline \multirow{2}{*}{ VAS } & Basal & $\begin{array}{l}\text { Immediately } \\
\text { postinjection }\end{array}$ & $\begin{array}{l}1^{\text {st }} 24 \\
\text { hour }\end{array}$ & 2 weeks & \multirow{2}{*}{$\begin{array}{c}\text { ANOVA } \\
\text { test }\end{array}$} \\
\hline & $\begin{array}{l}\text { Mean } \\
\pm \text { SD }\end{array}$ & Mean $\pm S D$ & $\begin{array}{l}\text { Mean } \\
\pm \text { SD }\end{array}$ & $\begin{array}{l}\text { Mean } \\
\pm S D\end{array}$ & \\
\hline Resting & $1.57 \pm 0.41$ & $1.33 \pm 0.52$ & $1.29 \pm 0.68$ & $1.22 \pm 0.75$ & 0.184 \\
\hline Movement & $7.15 \pm 2.83$ & $3.47 \pm 1.43$ & $3.15 \pm 1.65$ & $2.84 \pm 1.78$ & $<0.001 *$ \\
\hline Sleep & $6.63 \pm 3.15$ & $3.11 \pm 1.31$ & $2.72 \pm 1.55$ & $2.43 \pm 1.64$ & $<0.001^{*}$ \\
\hline Mean & $4.47 \pm 1.66$ & $2.81 \pm 0.57$ & $2.55 \pm 0.83$ & $2.17 \pm 1.22$ & $<0.001^{*}$ \\
\hline
\end{tabular}

Differences compared with basal value

Table 2: Distribution of patients as regard to basal, immediately postinjection, 1 st $24 \mathrm{hr}$ and 2 weeks after intervention Visual analogue score

\begin{tabular}{|c|c|c|c|}
\hline & $\begin{array}{c}\text { Partial } \\
\text { technique } \\
(\mathbf{n}=10)\end{array}$ & $\begin{array}{c}\text { Full } \\
\text { technique } \\
(\mathbf{n}=15)\end{array}$ & \multicolumn{1}{|c|}{$\begin{array}{c}\mathbf{P} \\
\text { value }\end{array}$} \\
\cline { 2 - 3 } & No (\%) & No (\%) & \\
\hline VAS $\leq \mathbf{2}$ & $5(50 \%)$ & $12(80 \%)$ & $\begin{array}{c}< \\
\mathbf{0 . 0 0 1}\end{array}$ \\
\hline $\begin{array}{c}\text { Improvement } \\
\text { in ROM }\end{array}$ & $4(40 \%)$ & $10(66.7 \%)$ & $\begin{array}{c}< \\
\mathbf{0 . 0 0 1 *}\end{array}$ \\
\hline $\begin{array}{c}\text { SPADI score } \\
\text { improvement }\end{array}$ & $5(50 \%)$ & $10(66.7 \%)$ & $\mathbf{0 . 0 2 8 *}$ \\
\hline
\end{tabular}

Table 3: Comparison between partial and full technique in frozen shoulder treatment

\begin{tabular}{||c|c|c|c||}
\hline & $\begin{array}{c}\text { Low } \\
\text { volume } \\
\text { injection } \\
(\mathbf{n = 5})\end{array}$ & $\begin{array}{c}\text { High volume } \\
\text { injection } \\
(\mathbf{n}=15)\end{array}$ & \multirow{2}{*}{ P value } \\
\cline { 2 - 4 } & No (\%) & No (\%) & \\
\hline VAS $\leq 2$ & $2(40 \%)$ & $11(73.3 \%)$ & $<0.001^{*}$ \\
\hline $\begin{array}{c}\text { Improvement } \\
\text { in ROM }\end{array}$ & $2(40 \%)$ & $9(60 \%)$ & $<0.001^{*}$ \\
\hline $\begin{array}{c}\text { SPADI score } \\
\text { improvement }\end{array}$ & $1(20 \%)$ & $9(60 \%)$ & $<0.001^{*}$ \\
\hline
\end{tabular}

Table 4: Comparison between Low and high volume injection in Subacromial bursitis treatment

\begin{tabular}{|c|c|c|c||}
\hline & $\begin{array}{c}\text { Extra- } \\
\text { articular } \\
\text { injection } \\
(n=5)\end{array}$ & $\begin{array}{c}\text { Intra-articular } \\
\text { injection } \\
(n=10)\end{array}$ & \multirow{2}{*}{ P value } \\
\cline { 2 - 3 } & No (\%) & No (\%) & \\
\hline VAS $\leq 2$ & $3(60 \%)$ & $8(80 \%)$ & $<0.001^{*}$ \\
\hline $\begin{array}{c}\text { Improvement } \\
\text { in ROM }\end{array}$ & $2(40 \%)$ & $8(80 \%)$ & $<0.001^{*}$ \\
\hline $\begin{array}{c}\text { SPADI score } \\
\text { improvement }\end{array}$ & $2(40 \%)$ & $7(70 \%)$ & $<0.001^{*}$ \\
\hline
\end{tabular}

Table 5: Comparison between Extra and intraarticular injection in Bicepital tenosynovitis treatment 
a

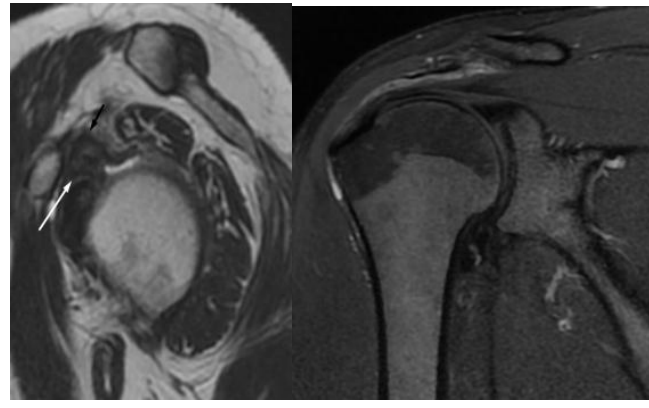

d

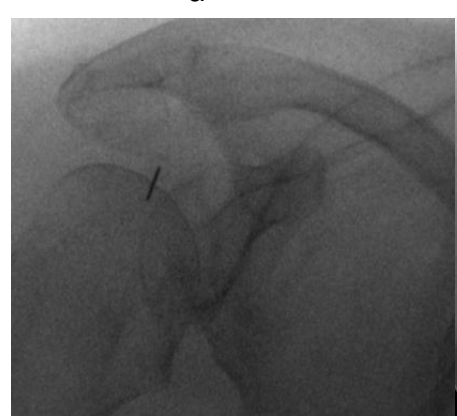

g

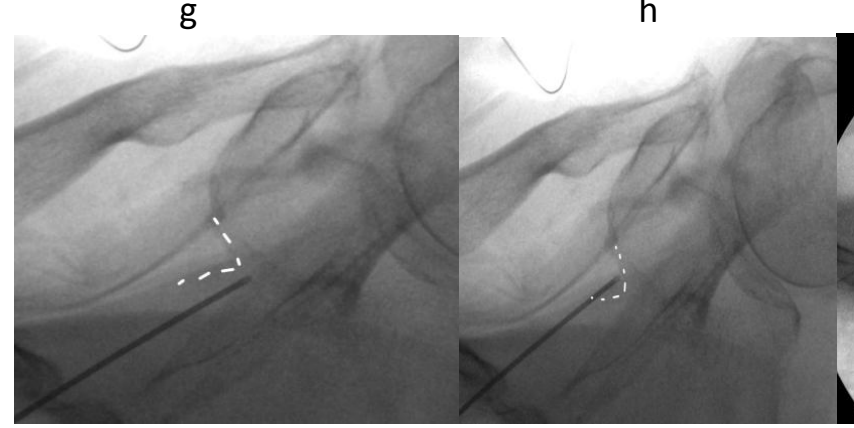

e
C

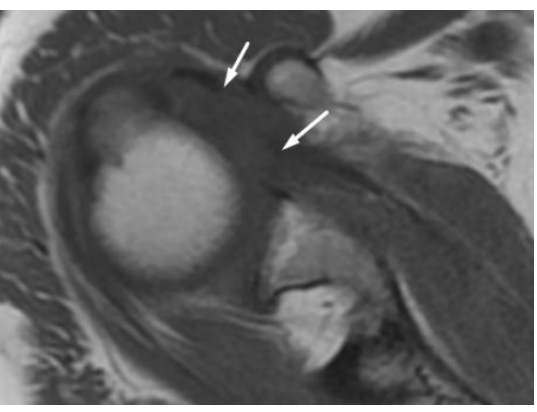
$f$

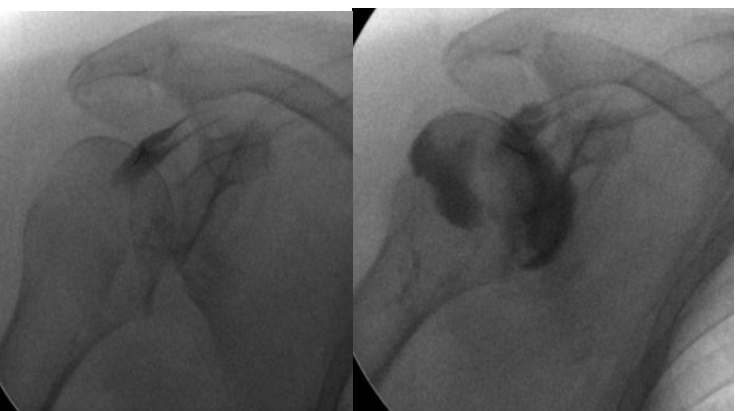

i

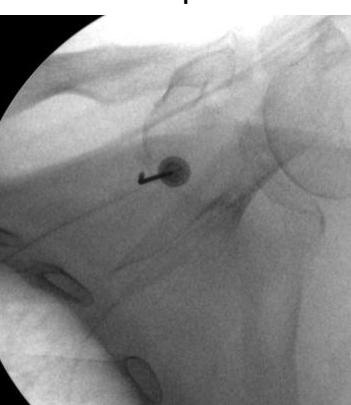

Case 1: female patient 70 Years presented with painful limited movements in all direction (frozen shoulder), selected MRI images ( $a, b$ and c) showing evidence of fibrosis within rotator interval (white arrow), and thickened coraco-humeral ligament (black arrow), patient underwent fluoroscopic guided hydro dilatation of glenohumeral joint capsule (images $d$, e and $\mathrm{f}$ ), then fluoroscopic guided pulsed radiofrequency of supra scapular nerve (images $\mathrm{g}, \mathrm{h}$ and $\mathrm{i}$ ) within supra scapular notch (dashed white lines).

a

b

c

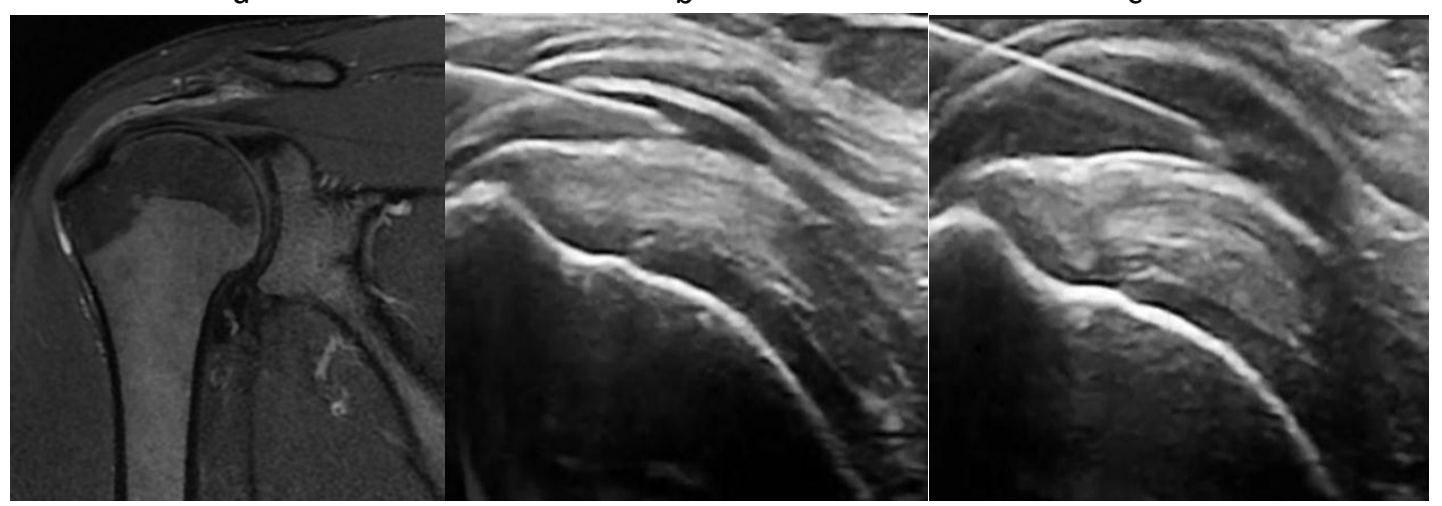

Case. 2: male patient 30 year old presented with anterior and lateral shoulder pain MRI showed evidence of subacromial bursitis, patient underwent ultrasound guided high volume hydro dissection of subacromial bursa. 


\section{DISCUSSION}

Shoulder pain is a prevalent symptom in orthopaedic and rehabilitative clinics. Proper detection is important to a therapy plan, as erroneous therapeutic strategies can lead to bad prognosis. for shoulder pain cases But there is no exploration of the distribution on the source of shoulder discomfort. ${ }^{8}$

The current study showed that regarding radiological interventions, patients with frozen shoulder treated by partial technique 10 (16.7\%) and full technique 15 (25\%), patients with Subacromial bursitis treated by Low volume injection $5(8.3 \%)$ and high-volume injection $15(25 \%)$ while in patients with Bicepital tenosynovitis treated by Extra-articular injection 5 (8.3\%) and intra-articular injection 10 (16.7\%).

There was a significant difference between basal, immediately, 1st $24 \mathrm{hr}$ and 2 weeks VAS after injection at movement, sleep and total mean score while there is no significant difference between basal, immediately, 1 st $24 \mathrm{hr}$ and 2 weeks VAS after injection at rest.

Our results were supported by study of AHMED \& AHMED, as they reported that among group with nerve block injection, all patients showed improvement in the first three months, but unfortunately at 6 months, 4 cases showed recurrence of pain, 3 of them $(30 \%)$ showed recurrence of pain to same severe pre-treatment level, while 1 case (10\%) showed a lesser extent being from mild to moderate, according to the VAS. ${ }^{9}$

Furthermore, Wang et al. ${ }^{10}$ revealed that Basic scores of all VAS evaluations were not very different across groups (pain at rest, at night and during overhead activities). While both groups indicated a significant decrease in the three scores one month after injection, Group 1 demonstrated rebounded pain at the 3-month follow-up. The conventional subacromial injection (Group 1) or dual target injection group were randomly allocated (group 2).

The present study showed that in frozen shoulder cases, full technique has significantly higher improvement in VAS, ROM and SPADI than partial technique $(\mathrm{p}<0.05)$. Among Bicepital tenosynovitis cases, Intra-articular injection has significantly higher improvement in VAS, ROM and SPADI than Extra-articular injection $(\mathrm{p}<0.001)$.

Scarpone et al. ${ }^{11}$ performed a prospective trial in 2013 with a forty five individuals refractory rotator cuff tendinopathy that showed significant improvements in pain, function and MRI results by single intralesional injection of PRP under ultrasound supervision. Also, Nourissat et al. ${ }^{12}$ analysis found that, irrespective of the site and kind of lesion, existing evidence did not justify the first line therapy of PRP. This component must be addressed prior to routine usage of PRP.

A prospective open-label non-randomized study from Tagliafico et al. ${ }^{13}$ experiment focusing on older people with large cuff tears demonstrated great improvement of pain and mobility ratings in the first four months of follow-up, but not in healthy group. The results of the treatment and untreated cases were not different after 5 months. Thus, researchers revealed that US guiding visco-supplementation is a good therapeutic approach in the first months of management.

\section{CONCLUSION}

We can conclude that interventional radiology has an effective role in management of chronic shoulder pain.

\section{REFERENCES}

1. Luime JJ, Koes BW, Hendriksen IJ, Burdorf A, Verhagen AP, Miedema HS, et al. Prevalence and incidence of shoulder pain in the general population; a systematic review. Scandinavian journal of rheumatology. 2004 Mar 1;33(2):73-81.

2. Hung CY, Chang KV, zçakar L, Wang TG, Chen WS. Can quantification of biceps peritendinous effusion predict rotator cuff pathologies? A retrospective analysis of 1352 shoulders ultrasound. Am J Phys Med Rehabil. 2016;95(3):161-8.

3. Zçakar L, Kara M, Chang KV, et al. Nineteen reasons why physiatrists should do musculoskeletal ultrasound: EURO-MUSCULUS/USPRM recommendations. Am J Phys Med Rehabil. 2015;94(6):e45-e49.

4. Sekizkardes M, Aydin G, zçakar L. Ultrasoundguided shoulder injection or ultrasound guides the shoulder injection? Standard vs state-of-the-art. Am J Phys Med Rehabil. 2018;97(5):e46.

5. Kostretzis L, Theodoroudis I, Boutsiadis A, Papadakis N, Papadopoulos P. Suprascapular nerve pathology: a review of the literature. Open Orthop $J$. 2017;11:140-53.

6. Fields, B.K., Skalski, M.R., Patel, D.B., White, E.A., Tomasian, A., Gross, J.S. and Matcuk, G.R., 2019. Adhesive capsulitis: review of imaging findings, pathophysiology, clinical presentation, and treatment options. Skeletal radiology, pp.1-14.

7. Sun Y, Zhang P, Liu S, Li H, Jiang J, Chen S, Chen $\mathrm{J}$. Intra-articular steroid injection for frozen shoulder: a systematic review and meta-analysis of randomized controlled trials with trial sequential analysis. The American journal of sports medicine. 2017 Jul;45(9):2171-9.

8. Tran G, Hensor EM, Ray A, Kingsbury SR, O'Connor P, Conaghan PG. Ultrasound-detected pathologies cluster into groups with different clinical outcomes: data from 3000 community referrals for shoulder pain. Arthritis research \& therapy. 2017 Dec;19(1):1-0.

9. AHMED SA, AHMED MB. Ultrasound Guided Radiofrequency Ablation of the Suprascapular Nerve Versus Injection Block Technique: A Comparative Study in Patients with Chronic Shoulder Pain. The Medical Journal of Cairo University. 2019 Sep 1;87:3859-64.

10. Wang JC, Chang KV, Wu WT, Han DS, Özçakar L. Ultrasound-guided standard vs dual-target subacromial corticosteroid injections for shoulder impingement syndrome: a randomized controlled 
trial. Archives of physical medicine and rehabilitation. 2019 Nov 1;100(11):2119-28.

11. Scarpone M, Rabago D, Snell E, Demeo P, Ruppert K, Pritchard P, Arbogast G, Wilson JJ, Balzano JF. 2013. Effectiveness of Platelet-rich Plasma Injection for Rotator Cuff Tendinopathy: A Prospective Openlabel Study. Glob Adv Health Med. Mar; 2(2):26-31.

12. Nourissat G, Ornetti P, Berenbaum F, Sellam J, Richette P, Chevalier X. 2015; Does platelet-rich plasma deserve a role in the treatment of tendinopathy. Joint Bone Spine 82: 230-4.

Tagliafico A, Serafini G, Sconfienza LM, Lacelli F, Perrone N, Succio G, Martinoli C. 2011. Ultrasoundguided viscosupplementation of subacromial space in elderly patients with cuff tear arthropathy using a high weight hyaluronic acid: prospective open-label non-randomized trial. Eur Radiol. 2011 Jan; 21(1):182-7. 